\title{
DESIGN AND INSTALLATION OF HIGH VOLTAGE CABLES AT SEA
}

\author{
LOUISE VÅBENØ \& OVE T. GUDMESTAD \\ University of Stavanger, Norway.
}

\begin{abstract}
Underwater telecommunication cables have been connecting continents since the 1860 s. These days large electric power cables are connecting countries to ensure optimization of energy use. When the production of energy from renewable resources, like wind and solar, are low, energy from other sources may be imported and vice versa. At the moment a cable is planned between Norway (for hydropower) and Scotland (for wind power). Furthermore, large electric power cables are needed offshore to bring electricity from offshore wind turbines to shore and cables are required to bring onshore generated electricity to offshore oil and gas platforms to reduce pollution. Over time, the process of laying cables at sea has developed into a state-of-the-art operation. Now these operations are becoming more technologically advanced and it is possible to lay large diameter electric cables over large distances. A particular challenge occurs in case an unplanned splicing/ jointing will be necessary. In this paper, we explore the design criteria for such cables and the procedures and challenges of installation and splicing. Furthermore, the effects of how dynamic motions of the vessel and sea influence the situation in deep water are explored. We have analysed the effects of waves on vessel motion, and how this may affect the cable during a jointing operation of two cable ends at different water depths. The effects of current forces on the cable are also analysed and how the cable reacts to both current and wave forces. This analysis method can assist in determining the weather criteria for a jointing operation to prevent excessive bending, compression or fatigue damage in the cable. One finding in the analysis is that there are different requirements for laying the cable and the jointing operations. The suitable sea states for jointing are more limited than for laying. When the vessel and the cable are standing still, all bending occurs at the same place in the cable, resulting in increased risk of fatigue damage, hence it is necessary with a calmer sea state for this kind of operation. The examples referred to in the paper are based on realistic assumptions; a summary of these assumptions is included. Furthermore, a HAZID, carried out for cable installation, shows that there are several risks and hazardous events that may occur during the installation operation in connection to the cables integrity. Identifying and handling these risks early may reduce both their probability of occurring and the related consequences.

Keywords: European electric grid, high voltage, installation of underwater cables, operations of large cables, underwater electric cables.
\end{abstract}

\section{INTRODUCTION}

Ninety-eight percent of the electricity used in Norway is generated at hydroelectric power stations. This power generation system is very flexible and emits low levels of $\mathrm{CO}_{2}$. A reduction or an increase in the Norwegian power production has, however, little effect on worldwide emissions of greenhouse gases as Norway has only 5.5 million inhabitants. On the other hand, by connecting Norway's power grid to the European continent's grid, Norway exports excess power when there is an abundant amount of water in the hydropower reservoirs and imports renewable energy from wind turbines when there is an excess amount of energy on the continent. The excess energy could even be used to pump water back into water reservoirs in the Norwegian mountains. In this way, the Norwegian reservoirs would act as batteries. European countries should in this way cooperate in order to achieve shared $\mathrm{CO}_{2}$ reduction goals.

New power connections between the countries' grids need to be established in order to create a Pan-European Transmission Network. By using high voltage subsea cables this is 
achievable. Many cables are already installed, but new cables are in the planning stage. The laying of cables is the key to combining the electrical resources from many countries.

Further to international power cables, large electric power cables are connecting offshore wind farms to the home country's electricity grid and some oil and gas platform in the Norwegian sector of the North Sea are now abandoning the large offshore electricity generators for renewable electricity from shore.

\section{INTERNATIONAL LONG-DISTANCE CABLES}

At the moment Norway has five international subsea cable connections; four connections to Denmark (Skagerrak 1-4) and one to the Netherlands (NorNed) with the capacity of 1700 MW and 700 MW, respectively, according to information provided by Ref. [1]. Two new cables, one to Germany and one to the United Kingdom (Fig. 1), will be installed and set into operation within the next 4 years. This will increase the transmission capacity by $2800 \mathrm{MW}$ and $1400 \mathrm{MW}$, respectively [1]. The North Sea Link is the world's longest interconnector.

\subsection{The North Sea link}

A license for a new cable interconnection between Norway and England was approved in 2013. This new connection, called the North Sea Link (NSL), will open for import and export of energy between Norway and England. It will contribute to UK's continuing large-scale development of clean wind and solar power

Statnett and UK's National Grid will both own $50 \%$ of the cable that is planned to go from Kvilldal in Norway and to Blyth in England. The cable route is divided into three parts, Lot 1, Lot 2 and Lot 3 with a total distance of $725 \mathrm{~km}$. The cable for Lot 1 is produced and laid by Nexans Norway AS, while cables for Lots 2 and 3, towards England, are laid by the Prysmian Group.

Lot 1 starts at the hydropower power station in Kvilldal and runs onshore from there to Hylen in Suldal. From Hylen it will be following the fjords to about $150 \mathrm{~km}$ in the North Sea towards Blyth, as seen in Figure 2. The features of the cable route through the fjords have

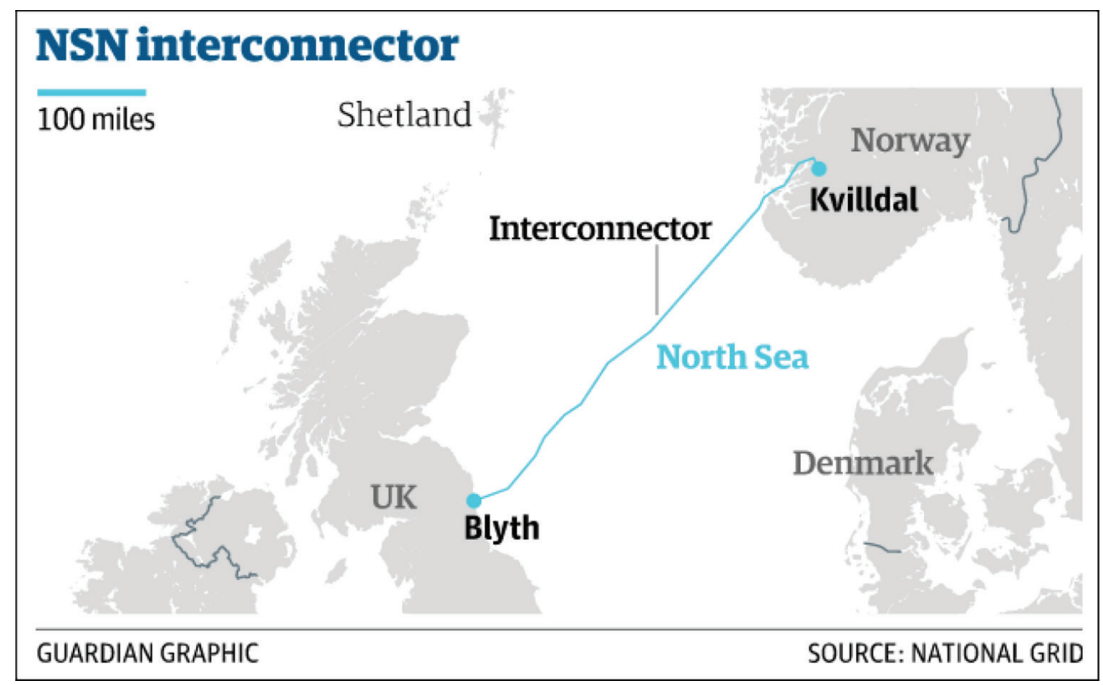

Figure 1: Subsea power cable connection under construction between Norway and UK. 


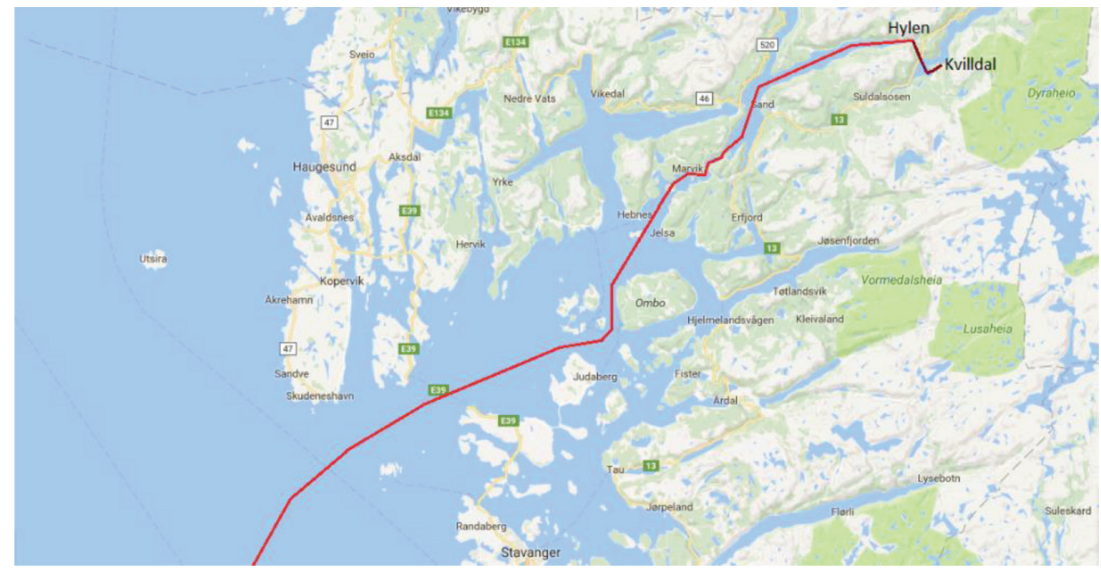

Figure 2: Cable route for Lot 1 of the NSL cable; From Kvilldal in Norway towards Blyth in England.

challenging parts, with water depths varying between deep water (550 $\mathrm{m}$ in Boknafjorden) and shallow water and narrow curves in the fjords. Using a vessel that can accommodate a load of 7000 tons, the cable ends need to be jointed together about every $140 \mathrm{~km}$ to reach across the entire distance. The best suitable locations for the cable to be jointed depend on a combination of the features of the cable route and the sea state.

\subsection{DC versus AC transmission cables}

When the need to transfer large quantities of power across the ocean arises, the question is whether to go for a high-voltage alternating current (HVAC) or a high-voltage direct current (HVDC) system. While DC flows through the whole conductor cross-section, the AC draws itself towards the conductor surface and the middle of the conductor is not contributing to the transmission. The effective cross section is reduced and the resistance increased. To transfer the same amount of power, the HVAC connection needs three cables whereas a HVDC connection only needs one. Figure 3 shows the power loss in a cable as function of distance, [2].

Total Power loss; HVAC vs. HVDC

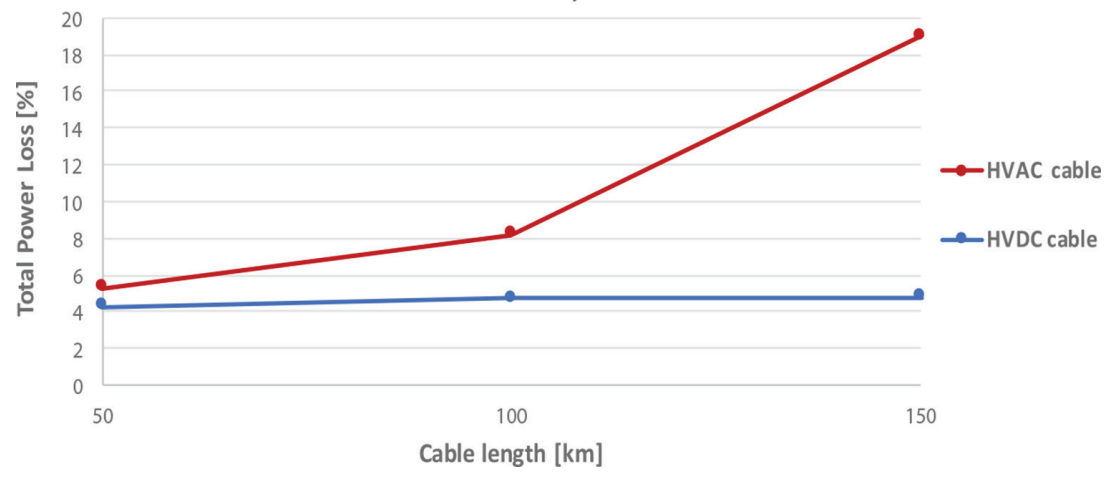

Figure 3: Total power loss in a HVAC and a HVDC system [2]. 
When using HVDC cable there is a need for converter stations at each end to transfer the electricity generated from AC to DC power and back again. The costs of converter stations are high, but when including material cost and power losses, the HVDC cable becomes economically favourable already at $50 \mathrm{~km}$, while the break-even price for overhead lines occur at a distance of $600 \mathrm{~km}$ [3]. The HVDC system is also known to be more stable and can change the direction of energy flow and power level quickly.

\subsection{The cable}

Producing cables are a very neat and time-consuming procedure. For high voltage cables, most cables are designed and tailor-made to fit each single project. As illustrated in the Figure, the general layout includes the conductor in the core of the cable. The insulation system is next, then a water barrier of lead and plastic, and armouring and an outer serving furthest out.

Conductors are made of copper or aluminium. In cases where weight is of critical concern, aluminium is more suitable as it has one third of the weight compared to copper. Copper, on the other hand, has much higher electrical conductive properties, and is therefore often preferred. The high conductivity results in a smaller cross section, and thus less insulation, armouring and other material are needed. The conductor comes in many shapes. A solid circle conductor, as seen in Fig. 4, is usually not used for higher cross sections than $400 \mathrm{~mm}^{2}$ and are thus limited to voltage $<150 \mathrm{kV}$ [4]. Larger conductors made of stranded round wires are well known and used over many years. The round shape causes small gaps in between the wires. To reduce these interstices, the conductor is compressed.

\section{CABLE INSTALLATION}

For the cable to last throughout its intended lifetime, it has to be able to withstand all mechanical stresses in all the phases of its life. This includes manufacturing, transportation and operation as well as installation. During installation, the water depth is the main variable when calculating the required tensional strength. The static force due to the weight of the cable hanging down from the vessel to the seabed is calculated as

$$
T_{s}=w^{*} d
$$

where $w$ is the weight of the cable in water per meter and $d$ is the maximum water depth. For simplification, the extra length between the laying wheel and water level is often neglected as

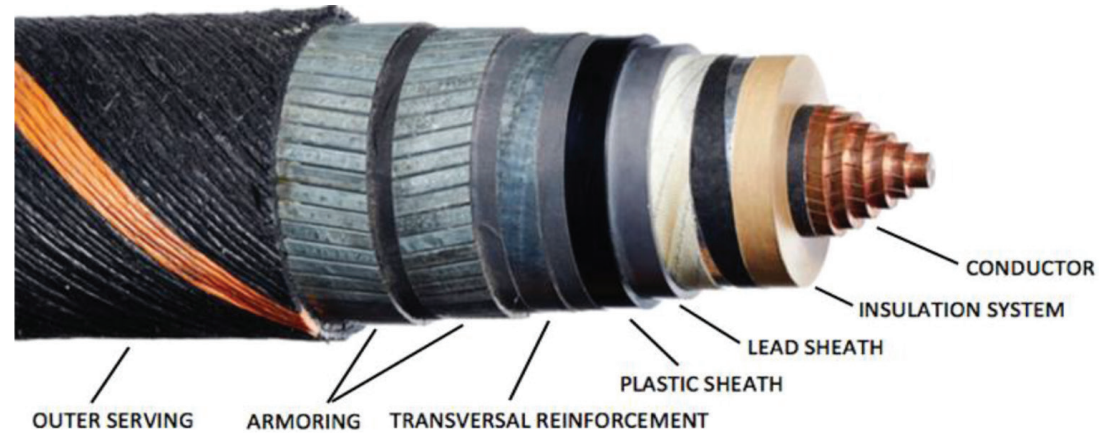

Figure 4: Submarine HVDC cable (Courtesy of Nexans Norway AS). 
it contributes very little to the total tension. To avoid compression and critically small bending radius in the cable, the cable is always held in tension at the touch down (TD) point. The additional horizontal tension translates to vertical tension at the top of the cable and causes the cable line to form a catenary shape. As the catenary length, $s$, is longer than a cable hanging straight down, the total tension becomes

$$
T=\sqrt{T_{0}^{2}+(w s)^{2}}
$$

where $T_{0}$ is the horizontal tension at TD.

The dynamic contribution to the tension is complex, as the forces can be affected by many parameters, such as weather conditions and the response amplitude operator (RAO) of the vessel. Due to ocean waves, the cable is also exposed to dynamic forces. The wave induced vessel motion causes the laying wheel or chute to move vertically. To account for these forces, the maximum vertical acceleration $b_{\max }$ of the wheel is found by

$$
b_{\max }=\frac{h}{2} *\left(\frac{2 \pi}{P}\right)^{2}
$$

assuming the movements are sinusoidal [4]. Here, $h$, is the maximum vertical movement, from peak to peak, and $P$ is the period, between the wave peaks. With $m$ being the mass of the cable hanging from the vessel, the maximum tension in the cable can now be found as

$$
T=T_{s}+\left(m * b_{\max }\right)
$$

It is mainly pitch and heave motions of the vessel that contribute to the vertical motion of the laying wheel, but how severe the motions are, will vary from vessel to vessel as they all have different motion characteristics (described by their RAOs). In reality, waves do not often have a fully sinusoidal waveform. They can be both steeper and shorter. The dynamic forces can also be larger than anticipated by the sinus formula, due to superimposed waves from different directions and sources. The steeper waves result in a higher vertical acceleration in the laying wheel. A weather forecast is, furthermore, rarely $100 \%$ accurate, and one should always have in mind that only a few unexpected waves of great amplitude can be enough to damage the cable. For a conservative approach, one should use a value of $b_{\max }=6 m s^{-2}$ [4], especially if no documentation on the vessel's vertical behaviour is present.

The updated version of the 'Cigré test' recommendation for submarine power cables known as Electra No. 171 [5], presents equations for finding an estimate of the maximum tensile force occurring in the cable during installation. The tensile forces during cable testing have to be larger than any tensile forces experienced throughout the whole installation process. The equations are valid for cables of voltages higher than $30 \mathrm{kV}$ AC or $60 \mathrm{kV} \mathrm{DC}$. For a maximum water depth of $500 \mathrm{~m}$ the test tension is found as

$$
T=1.3 * w^{*} d+H
$$

with $H=0.2 * w * d$ being the maximum bottom tension during installation, and always above $40 * w[\mathrm{~N}]$. To include the contribution from dynamic forces, a multiplication factor of 1.3 is added. By using this approach, the significant wave height is limited to $H_{s} \leq 2 \mathrm{~m}$. For more severe weather, one should follow the procedure below for water depths beyond $500 \mathrm{~m}$, where the movement of the laying wheel is included. The expected maximum tension is 


$$
T_{E}=w^{*} d+H+D
$$

where $D$ is the dynamic tension, and a combination between the drag force and the inertia force is acting on the cable;

$$
D=\sqrt{D_{I}^{2}+D_{D}^{2}}
$$

Inertia force:

$$
D_{I}=1.1 * \frac{h}{2} * m * s * \omega^{2}
$$

where, as stated previously, $h$ is the maximum vertical displacement of the laying wheel, $m$ is the cable mass per meter, $s$ is the catenary shaped length of the cable, $\omega=2 \pi / t$ is the circular frequency of the laying wheel movement. The added mass that will move with the cable is accounted for by a factor of 1.1 .

Drag force:

$$
D_{D}=500 * O D * R^{0.9} *(h \omega)^{1.8}
$$

where $O D$ is the outer diameter of the cable and the term $R, R=H / w$, is the bending radius close to TD. The term is composed after a thorough study, and to ensure a conservative result. The constants 500, 0.9 and 1.8 were determined when using SI units. The worst allowed weather conditions and the planned installation vessel should be the basis for the movement and period used for the calculations. The maximum expected wave height $H_{\max }$ is found by $H_{\max }=H_{s}^{*} 1.9$ and should be the basis for estimating $h$, the vertical movement of the laying wheel.

The test tension is now found by adding a safety factor to the expected tension:

$$
T=1.1 T_{s}+1.3 T_{D}
$$

where $T_{s}=w^{*} d+H$ is the static tension and $T_{D}=D$ is the dynamic tension.

For more detailed discussion, see Ref. [6]. Regarding factors influencing the installation, see Fig. 5.

When designing the cable armouring, one needs to know which sea state to design for. The sea state is affected by the season in which the cable is to be installed and the weather statistics of the area. The number of suitable weather windows is affected by the sea state one

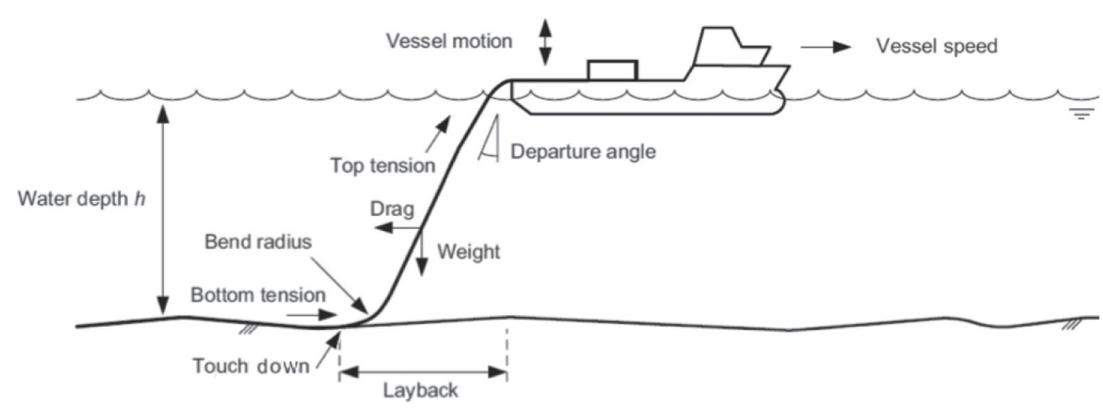

Figure 5: Factors influencing the laying procedure [7]. 
chooses to design for, which also affects the risk associated with the cost caused by termination of operation and duration of the installation.

The assumption of applying a factor of 1.1 on the inertia force due to added mass (eqn (8)) is considered realistic as we here have a slender structure that will not involve considerably volumes of water moving with the cable. The safety factors suggested in eqn (10) are safety factors for static and dynamic loads normally used in the industry. It should also be noted that experience [8] shows that the bottom tension $(40 * w[\mathrm{~N}])$ must be considerable to avoid buckling in the lower bend due to a bending radii that is too small.

\subsection{Cable installation procedures}

A Cable-Lay Vessel (CLV) is a ship or barge specially built for the sole purpose of laying and repairing subsea cables. Accompanying the CLV are often smaller tug boats stored on the CLV deck when not in use or during transit.

Keeping the correct position at sea is of crucial importance for a successful cable lay. Waves and currents will push on the vessel for it to move. Once the cable is being paid out, it will be pulling on the vessel. The tension in the cable from its own weight and the bottom tension will pull the vessel backwards. A wrong vessel position can cause the bottom tension to decrease to a minimum, or in worst case, result in compression forces and damage in the cable at TD.

Most new CLV rely on a dynamical position (DP) system with powerful thrusters. By having multiple thrusters, one can manage and keep the required position of the vessel at all time. The thrusters can be located both in the bow and stern as well as in the centre underneath the vessel. The vessel keeps its location according to a global coordinate system. To keep the TD point of the cable at its required position, it coordinates its local location to the global location of the vessel. The entire route of the cable is settled upon before the laying starts after a thorough route survey. The vessel's DP system follows these coordinates at all time to make sure the cables TD is at the correct location. Being 1-2 meter off track is usually acceptable, especially where the seabed is flat and without any hinders. On a rocky seabed, the accuracy of the cable-lay becomes more critical to avoid laying the cable over sharp rocks, and rather in between them.

The cables are stored on large reels or in tanks. The same storage options on shore can be used on the vessel during installation. The storage methods have different qualities and the type of cable and armouring may influence the decision. A vertical reel gives the advantage of simple installation where breaks can be applied directly to the reel flange. It is however, hard to control at deep water due to the high tension in the cable. The high centre of gravity (COG) will also result in limited capacity to maintain the stability of the vessel and is more common for smaller projects that do not require large load capacity. A horizontal reel will lower the COG and increase the capacity. Some tension can be taken by the reel to aid the external tensioners. The packing of the cable, vertically around the core of the reel, can be tricky if not done right. For the cable to stay in place and prevent disorder, it needs to be held in tension at all times.

Both the vessel and the cable are subjected to external forces due to the weather situation. The waves have a large impact on the vessel motions. And the vessel's pitch motions resulting from waves cause the laying wheel at the stern of the vessel to move up and down. This motion will both change the tension in the cable and change the departure angle where the cable leaves the laying wheel. These vessel motions combined with the speed of the vessel 
will change the tension in the cable all the time, which then changes the location of the TD and the bend radius in the cable. Current following the vessel's direction (from behind), furthermore, causes higher tension in the cable and current moving against the vessel causes a lower tension in the cable as it is being 'lifted'.

The ocean bottom is often uneven. If it is not possible to avoid or lay around obstacles, one should attempt to shorten the free spans, as suspended cables being exposed to ocean currents could experience vortex induced vibrations and fatigue damage locally. By reducing the bottom tension, the cable will follow the bathymetry.

\subsection{Cable jointing}

When the distance of the cable installation increases, the number of cable joints necessary to complete a project increase. Cable jointing occurs during, at the end or after an installation, on board the CLV inside a special built jointing house. The operation is a weather sensitive task due to its duration. Depending on the type and complexity of the cable, a jointing operation can take as much as 8 till 12 days, [8]. During cable installation, cables are jointed together at the end of a cable length. Before going back to shore to retrieve a new cable length, the end of cable A is carefully sealed and laid down at the seabed. When returning with the new cable, cable B, cable A is picked up from the seabed and comes back up over the laying wheel, into the tensioner and onto the turntable and then further over to the jointing table.

During the jointing, the cable is held still at the vessel, as any movement of the cable on board the vessel will disturb the jointing process. Contrary to the laying where the cable constantly moves over the laying wheel, the cable is staying still over the wheel, and excessive cyclic bending of the cable become critical. Wave induced vessel motions, like pitch, roll and heave, result in change in departure angle and residual bottom tension over time. To get a successful operation one needs to assure adequate tension at all times and to keep the departure angle change to a minimum. By establishing weather criteria for the operation, one can determine whether to start, delay or abort a jointing operation.

How many cycles of bending a cable can endure without getting fatigue damage need to be tested at a laboratory and will depend on the degree of bending and type of cable.

\subsection{Cable installation criteria}

When installing a cable at the seabed there are certain criteria that need to be fulfilled to ensure a successful installation with a fully functional cable. These criteria are important at different stages of the installation, some of which are critical during laying, some during jointing of two cables, and some after installation to protect the cable. A summary of these criteria is represented in Table 1 [6].

\subsection{Installation analysis}

A HAZID analysis needs to be performed in order to identify all potential hazards related to the operation. It is important to conduct this analysis before and during the planning of a specific installation. The HAZID will show a wide range of accidents of which the cables integrity would be compromised, including challenging weather and equipment failure. By highlighting the many hazardous events that may occur, one can implement adequate risk reducing measures. 
Table 1: Criteria for installation of a submarine cable [6].

\begin{tabular}{|c|c|c|}
\hline Stage & Criteria & Response description \\
\hline \multirow[t]{3}{*}{ Cable laying } & $\mathrm{T}<\mathrm{T}_{\text {allowable }}$ & $\begin{array}{l}\text { Reduce the top tension, while keeping } T>T_{\text {critical }} \\
\text { Top tension must never exceed cable or CLV's } \\
\text { tension capacity. }\end{array}$ \\
\hline & $T_{\text {residual bottom tension }}>0$ & $\begin{array}{l}\text { Increase } T>T_{\text {critical }} \text { to assure no compression in } \\
\text { cable and no looping of cable }\end{array}$ \\
\hline & $R_{\min }>M B R$ & $\begin{array}{l}\text { Increase tension. No bending in cable smaller than } \\
\text { the cables MBR-limit. Tension in cable must always } \\
\text { be } T>T_{\text {critical }}\end{array}$ \\
\hline Cable jointing & $\begin{array}{l}\text { Cyclic bending < Fatigue } \\
\text { limit }\end{array}$ & $\begin{array}{l}\text { Cyclic bending of cable must never exceed fatigue } \\
\text { limit }\end{array}$ \\
\hline \multirow[t]{6}{*}{ Cable protection } & $\begin{array}{l}\text { Flat seabed surface } \\
\text { (desirable) }\end{array}$ & Route survey, seabed clearing \\
\hline & No point load on cable & $\begin{array}{l}\text { Reduced bottom tension over irregular seabed to } \\
\text { avoid cable suspension, while keeping } R_{\min }>M B R \\
\text { and } T>T_{\text {critical. }}\end{array}$ \\
\hline & No VIV in cable & $L_{s} / D<30^{[1]}$, minimize length of suspensions \\
\hline & Cable stability & $\begin{array}{l}\text { Avoid suspensions if possible. Cable protection: } \\
\text { Burial, rock placement, external protection }\end{array}$ \\
\hline & $\begin{array}{l}\text { No snag- or impact load } \\
\text { in cable }\end{array}$ & $\begin{array}{l}\text { Cable protection: Burial, rock placement, external } \\
\text { protection }\end{array}$ \\
\hline & No exposure of cable ${ }^{[2]}$ & Inspection, re-burial, external protection \\
\hline
\end{tabular}

[1] Where $L_{s}$ is the suspension length and $D$ is the outer diameter of the cable.

${ }^{[2]}$ Where protection is needed, to ensure stability and safety of the cable.

The angle of departure of the cable from the installation vessel is critical to ensure a certain tension level at the bottom and thus a sufficiently large bending radius in the lower bend. The computer program Orcaflex [9] has been used [6] to analyse the sensitivity on the on-bottom tension. Furthermore, the current is critical to ensure the necessary tension. With strong current, it becomes difficult, however, to use the departure angle of cable as a measurement for tension calculations. Current at 0 degrees (in line with the vessel movements) push the cable down, minimizing the angle and increasing the tension, while current at 180 degrees (coming against the vessel) lifts the cable, decreasing the tension. Currents from the side will lead to the offset of the cable touch-down point.

Dynamics during jointing of cable ends is of high concern. A study has been carried out [6] to find the limiting sea state for a realistic case. As the location of jointing is unknown, the main variables are wave direction, wave height and wave period, current direction and strength, water depth and initial residual tension in cable.

Assumptions used in the analysis:

- Vessel is same as the default vessel in the OrcaFlex software, [9];

- The cable is of the type planned for North Sea crossing, Table 2, [6];

- The cable is tested in a lab to see how many cycles of bending it can handle [8]; - very high number of cycles less than 1 degree, - about 12500 cycles of 1-2 degrees; 
Table 2: Cable data used for tension calculations and OrcaFlex simulations.

\begin{tabular}{|l|c|c|c|}
\hline \multicolumn{1}{|c|}{ Cable data: } & Sign: & Value: & Unit: \\
\hline Cable diameter & OD & 0,126 & {$[\mathrm{~m}]$} \\
\hline Weight in air & wd & 51 & {$[\mathrm{~kg} / \mathrm{m}]$} \\
\hline Weight in water & ww & 40 & {$[\mathrm{~kg} / \mathrm{m}]$} \\
\hline Bending stiffness & & 30 & {$[\mathrm{kNm} 2]$} \\
\hline Axial stiffness & & 419 & {$[\mathrm{MN}]$} \\
\hline Torsional stiffness & & 45 & {$[\mathrm{kNm} 2 / \mathrm{rad}]$} \\
\hline Ultimate strength & & 70 & {$[\mathrm{ton}]$} \\
\hline Minimum bending radius & MBR & 3 & {$[\mathrm{~m}]$} \\
\hline
\end{tabular}

- or about 500 cycles of $2-4$ degrees;

- or about 80 cycles of $4-6$ degrees;

- if exceeding these numbers, there is high risk of fatigue damage.

- 10 min of simulation represents a valid representation of how the vessel and cable behave in the different sea states.

The 10 min of dynamic simulations are done using the OrcaFlex software where data regarding tension and cable bending is used. Criteria assumed for residual bottom tension are set according to Table 3. For every simulation, the bottom tension is evaluated and an acceptance wave condition is set according to the lowest bottom tension.

Criterion for the bending in cable over the laying wheel is dependent on the degrees of angle change. For every simulation, angle data of the cable when leaving the wheel is gathered, and the bending cycles are split into groups, dependent on the angle of the bending. As stated in the assumptions, bending less than 1 degree is assumed to have very little effect on fatigue and is therefore not considered further. Bending between 1 and 2 degrees and higher are of concern, and the criteria are as seen in Table 4. The acceptance level is set according to how long time the cable can handle the wave load without being concerned about fatigue. In the 'green' level, the cable should, depending on the duration of the jointing operation, be able to endure the wave loads throughout the entire jointing operation, as the wave loads result in very little

Table 3: Sea state acceptance-level criteria for residual bottom tension in cable.

\begin{tabular}{|c|c|l|}
\hline \multicolumn{2}{|c|}{ Residual bottom tension } \\
\hline $\begin{array}{c}\text { Acceptance } \\
\text { level }\end{array}$ & Lowest measured value & \multicolumn{1}{|c|}{ Comment } \\
\hline & $>500 \mathrm{~kg}$ & No compression, low risk of loops \\
\hline & $>300 \mathrm{~kg}$ & No compression, loops may happen \\
\hline & $>0 \mathrm{~kg}$ & No compression, risk of loops \\
\hline & 1 time "<0 kg" & Risk of compression, risk of loops \\
\hline & $\leq 3$ time "<0 kg" & High risk of compression and loops \\
\hline & $\geq 4$ times "<0 kg" & Very high risk of compression and loops \\
\hline & Not applicable; No/rarely waves in this range \\
\hline
\end{tabular}


Table 4: Sea state acceptance-level criteria for cable bending over laying wheel.

\begin{tabular}{|c|c|l|}
\hline \multicolumn{3}{|c|}{ Cyclic bending in cable at departure of laying wheel } \\
\hline $\begin{array}{c}\text { Acceptance } \\
\text { level }\end{array}$ & $\begin{array}{c}\text { Number of 1-2 degree } \\
\text { bending / 10 min }\end{array}$ & \multicolumn{1}{c|}{ Comment } \\
\hline & $\mathrm{x} \leq 4$ & Can withstand this loading over entire jointing operation \\
\hline & $\mathrm{x} \leq 7$ & Risk of fatigue damage after 12 days \\
\hline & $\mathrm{x} \leq 10$ & Risk of fatigue damage after 8 days \\
\hline & $\mathrm{x} \leq 15$ & Risk of fatigue damage after 5 days \\
\hline & $\mathrm{x} \leq 28$ & Risk of fatigue damage after 3 days \\
\hline & $41 \leq \mathrm{x}<60$ & Risk of fatigue damage after 2 days \\
\hline & $\mathrm{x} \geq 41+$ higher angles & Risk of fatigue damage in less than 2 days \\
\hline & Rot fatigue damage in less than 1 day \\
\hline & Not applicable; No/rarely waves in this range \\
\hline
\end{tabular}

cyclic bending in the cable per time unit. After that, the jointing may have to be terminated, unless the sea state of concern appears later or towards the end of the jointing process.

We have suggested assumptions to be used for the analysis as well as the fatigue criteria as quoted in Tables 3 and 4. These assumptions are in line with suggestions by an installation operator [8]. These assumptions are made to show the method for installation analysis. For a real project, fatigue testing of the cable is required to obtain the correct criteria to be used for said project.

\section{RECOMMENDATIONS FROM THE ANALYSIS}

The key findings from the analysis is related to how different sea states affect the jointing operation of two cables, which could take from 8 to 12 days [8]. Most cable-lay vessels have the chute or laying wheel at the stern of the vessel. During a jointing operation, the most critical parameters in a cable are the horizontal bottom tension and the cyclic cable bending at the departure point of the laying wheel. This is because the cable needs to stand still over the laying wheel throughout the entire jointing procedure and all bending will occur at the same point. This bending in the cable can be a limiting factor for allowable sea states during time consuming jointing operations. With the cable entering the water at this location, the cable is very sensitive to the wave induced vessel motions. Cable movements at sea water level are highly affected by the pitch motion of the vessel. By heading the vessel perpendicular to the wave direction, the cable movements are reduced significantly, although the associated roll motion of the vessel taking waves broadside, makes working on the vessel uncomfortable.

The cable behaves different during laying in deep water and shallow water. Although the initial residual bottom tension is the same for all water depths analysed, the tension seems to be more sensitive to the wave induced vessel motions in deep water than in shallow water, especially in waves with short wave period. Rapid movements could cause the cable to loop and bend beyond its limitations, and the computer simulation of the installation would automatically be aborted.

To obtain an adequate tension in the cable, the cable departure angle should be is larger in shallow water than in deep water. The change in departure angle due to vessel motions, and hence the bending of the cable, is more sensitive to the wave induced vessel motion in 
shallow water when this angle is larger, than in deep water. In water depth of $500 \mathrm{~m}$ and above, the initial departure angle becomes very small, and any further changes in depth have no effect on the cyclic bending due to vessel motion. To reduce the cable bending in shallow water $(100 \mathrm{~m})$, smaller initial values of the tension were tested. A small improvement in bending is seen, but the main outcome was less control of the bottom tension with higher risk of looping and compression in the cable.

When jointing in areas with strong current, one needs to take the effect of the current's direction into account when determining if the sea state is acceptable or not. A current at 0 degrees (from behind) has an improving effect on the operation. The current reduces the departure angle and hence the cyclic bending of cable. The control of the bottom tension is also increased, resulting in less risk of looping and compression. A current at 180 degrees has the opposite effect, and cable jointing in this position should be avoided. The risk of looping and compression in the cable increases significantly as the current is reducing the tension and increasing the departure angle. At 112.5 degrees, the current has minor effect on tension and bending, but could have an effect on the touch down location of the cable as strong current can move the cable out of its path. As the vessel is not changing position or heading during the jointing, this should not be very critical. During laying, however, the cable would be laid outside of its planned route, which can lead to other issues, like the cable getting too close to on-bottom structures or seabed features, e.g. large rocks and boulders. This is not desirable.

In-line jointing of cables only require one laying wheel for the operation. The wheel was moved to the centre of the stern in order to analyse the location's effect during jointing. Centralizing the wheel had little to no effect on the bending of the cable, but a noticeable improvement on the bottom tension in the cable. At the centre location, the cable is less exposed to the roll motions of the vessel and can tolerate the effect of higher waves.

Throughout the analysis, we identified that the success of a jointing operation is highly dependent on the conditions of the sea state. Using the Orcaflex software's default vessel, the limiting sea state for cable jointing was found to be $\mathrm{H}_{\mathrm{s}}$ equal to $2.5 \mathrm{~m}$. The benefit of reducing the time it takes to prepare a connection offshore is obvious as one then could do the connection within a weather window forecasted by meteorologists.

\section{CONCLUSIONS}

Submarine cables for transfer of electric power over long distances offshore can be important to secure efficient utilization of renewable energy sources. It should be noted that the cable would have to carry direct electric current (DC) to limit the power loss during the transfer. Furthermore, the limiting wave conditions for the laying can be identified where the concern is the limiting on-bottom tension and the bending radius in the lower cable bend. However, the main concern is related to cable jointing where fatigue damage of the cable may be experienced.

The analysis method presented in this paper can be a guide to assist when planning future cable installations. This method alone should, however, not be used to conclude whether the sea state is acceptable or if the cable will experience compression, looping or fatigue damage. It is very important to include the test results of the exact cable type that is to be installed, as different types of cables will have different limitations. Experience from previous projects should also be included to establish whether the software is more conservative than it needs to be, and hence its reliability in real-life situations. Including more data about the weather, sea state and seabed features at the location of the installation in the analysis will increase the reliability of the results. 
A HAZID analysis identifying hazardous events that may occur should be carried out. By highlighting the many risks, before the installation starts, the HAZID results will increase the awareness throughout the entire process.

The vessel's RAO will have a huge impact on the results regarding the cable jointing and may increase the number of suitable sea states. For a vessel with less pitch motions, one could argue that it would be better to be heading into the waves, instead of the 90 degrees as recommended in this paper. This would be better for the cable, but it would also increase the crew's comfort tremendously.

Although the results from this analysis showed only a small amount of sea states to be suitable for the jointing operation, the technology in this field is continuously developing. New equipment and procedures are being developed, making the jointing operation quicker and more suitable for rougher sea states. By developing solutions for faster jointing, one could increase number of feasible situations because one could perform the operation in a more challenging sea state or within a shorter weather window. The submarine power cable industry can adopt practices and technology from other industries. The top tension in the cable need to be kept below the cable's and the vessel's tension capacity during the entire installation. Further development of installation methods for deep water may be necessary, as the tension can quickly become very high, especially in rougher sea states.

\section{ACKNOWLEDGEMENTS}

The first author will like to thank Lars A. Solberg of Nexans Norway AS for sharing knowledge about power cables and subsea cable installation.

\section{REFERENCES}

[1] STATNETT SF., Kabel til England [Online], available at http://www.statnett.no/Nettutvikling/Kabel-til-england/ (accessed 05 February, 2017).

[2] May, T.W., Yeap, Y.M. \& Ukil, A., Comparative evaluation of power loss in HVAC and HVDC transmission systems. IEEE Region 10 Conference (TENCON), Singapore, 2016.

[3] Kalair, A., Abas, N. \& Khan, N., Comparative study of HVAC and HVDC transmission systems. Renewable and Sustainable Energy Reviews, 59, pp. 1653-1675, 2016.

[4] Worzyk, T., Submarine Power Cables; Design, Installation, Repair, Environmental Aspects, Springer-Verlag Berlin Heidelberg: Berlin, Germany, 2009.

[5] CIGRÉ WORKING GROUP B1.43 Recommendations for mechanical tests on submarine cable, 9th International Conference on Insulated Power Cables, Versailles, 2015.

[6] Våben $\varnothing$, L., "Design, installation and operation of high voltage cables at sea", MSC Thesis, University of Stavanger, June 2017.

[7] DNV GL AS, DNV-RP-J301, Subsea Power Cables in Shallow Water Renewable Energy Applications, Høvik, Oslo, Norway, 2014.

[8] Solberg, L.A., Personal communication, employee in Nexans Norway AS, 2017.

[9] ORCINA. OrcaFlex [Online]. Available: https://www.orcina.com/SoftwareProducts/ OrcaFlex 